\title{
Developing a System Framework for China's Natural Resources Balance Sheet From the Perspective of Sustainable Development
}

\author{
Pinghua Chen ${ }^{1}$, Huiru $X^{2}{ }^{2}$, Shuiguang Chen ${ }^{3}$, Yuping Shang ${ }^{4}$, Baoying Zhang ${ }^{2}$ and \\ Xin Zhao ${ }^{5 *}$
}

${ }^{1}$ School of Accounting, Fujian Jiangxia University, Fuzhou, China, ${ }^{2}$ School of Economics, Fujian Normal University, Fuzhou, China, ${ }^{3}$ School of Public Administration, Fujian Agriculture and Forestry University, Fuzhou, China, ${ }^{4}$ School of Urban and Regional Science, Shanghai University of Finance and Economics, Shanghai, China, ${ }^{5}$ School of Statistics and Applied Mathematics, Anhui University of Finance and Economics, Bengbu, China

\section{OPEN ACCESS}

Edited by:

Gagan Deep Sharma, Guru Gobind Singh Indraprastha University, India

Reviewed by: Yuqi Tu,

Yanshan University, China Feiyang Cheng,

Tianjin University, China

*Correspondence: Xin Zhao zhaoshin_1993@163.com

Specialty section: This article was submitted to Environmental Economics and Management,

a section of the journal Frontiers in Environmental Science

Received: 01 November 2021 Accepted: 06 December 2021

Published: 17 January 2022

Citation:

Chen $P, X u H$, Chen S, Shang $Y$, Zhang $B$ and Zhao $X$ (2022) Developing a System Framework for China's Natural Resources Balance

Sheet From the Perspective of

Sustainable Development.

Front. Environ. Sci. 9:807092.

doi: 10.3389/fenvs.2021.807092
Exploring and compiling a natural resource balance sheet is of great significance for improving both natural resource and environmental management and for realizing sustainable social and economic development. Based on a literature review of previous studies, in this study, we analyzed the composition, measurement methods, and methods used to acquire data of the major elements used in a natural resource balance sheet, as well as determined that the balance formula for the sheet should comprise natural resource assets, natural resource liabilities, and the benefits of natural resources. A basic report format for the natural resource balance sheet was compiled on this basis.

Keywords: natural resources, balance sheet, resource efficiency, sustainable development, China

\section{INTRODUCTION AND LITERATURE REVIEW}

Sustainable development should meet current needs without weakening the ability of future generations to meet theirs (Bansal et al., 2021; Zhao et al., 2022). To achieve this, current economic growth needs to be coordinated with societal, resource, and environmental protection requirements. Achieving sustainable economic development also necessitates the protection of natural resources and the environment on which human survival depends, such as the atmosphere, freshwater, ocean, land, and forests, so that future generations can inherit an Earth that is not damaged beyond repair.

However, the current global support for natural resources and the environment on which economic growth depends is unsustainable, and resource and environmental problems are critical global issues. In view of this, the Chinese government first proposed the concept of a natural resource balance sheet (NRBS) in the Third Plenary Session of the 18th Central Committee of the Party in 2013. In this respect, an accounting theory method for preparing balance sheets is used to classify all the natural resource assets within the country or in a region, and the contents are then aggregated and statements are compiled. The aim of a NRBS is to reflect the basic stock of the country's natural resources at a particular point in time, but it can also reflect changes in the flow of such resources within a certain timeframe. Since 2014, the requirements for preparing NRBSs have been further clarified by the Chinese government, and pilot work has been conducted for preparing these sheets in Huzhou, Chishui, Yan'an, Hulunbuir, and other regions. Although staged progress has been made in preparing China's NRBS, certain problems remain, such as the immature report framework structure and unreliable data acquisition. Therefore, exploring the techniques and methods used to prepare 
NRBSs is not only a fundamental strategic requirement for constructing a national ecological civilization system, but it is also necessary for the departments that prepare them. This study has important scientific and practical significance.

The preparation and application of NRBSs are an important part of an environmental economic accounting system. As early as the 1920s, Morehous and Ely (1924) proposed the concept of natural resource asset management, and the theoretical environmental economics system has been continuously improved since the development of global economies following the Second World War. For example, in the 1960s, scholars such as Goldsmith and Revell (1965) began to compile a NRBS for the United States. In 1978, the Norwegian government conducted natural resource accounting for the first time and developed an initial natural resource accounting system that included natural resources (such as forests, water, and land) as accounting objects (Alfsen, 1987). In 1985, the Netherlands began compiling trial balance sheets for certain natural resources, such as energy, forests, and land (Gerlagh et al., 2002), and in 1990, the Mexican government accounted for the value and physical quantity of resources such as forest, soil, water, land, and oil (Burritt and Saka, 2006). Based on such theoretical and practical research, the United Nations Statistics Office established the comprehensive environmental economic accounting system (SEEA-1993) in 1993. This system incorporates resource assets into the system of national accounts and builds a system of resource accounting and national economic accounting. The effective link between the two has established a basic theoretical framework for resource and environmental accounting for the international community (Wang and Yuan, 2020). Since 2012, the United Nations Statistics Office and other international organizations have further improved the comprehensive environmental and economic accounting system, and the System of Environmental-Economic Accounting 2012 (SEEA-2012) has become the latest and most authoritative international framework for natural resource asset accounting. In this framework, the basic principles of accounting are summarized for seven natural resource assets (mineral and energy resources, land resources, soil resources, timber resources, aquatic resources, other biological resources, and water resources), and calculation formulas and tables used to process the data of these assets are provided (Sharma et al., 2021a).

Many studies have since discussed the preparation of NRBSs based on the SEEA-2012. For example, Kassai et al. (2012) measured and classified natural resources into environmental assets, liabilities, and equity using basic accounting principles and then used resource data from seven countries including the United States, Japan, Germany, and China, to conduct a resource ecological economic benefit evaluation. Geng et al. (2015) used the SEEA-2012 as a foundation for studying and compiling a NRBS based on water, soil, and minerals. In addition, Obst and Vardon (2017) analyzed the accounting standards associated with land, energy, and water resource accounts compiled by the Australian Bureau of Statistics and determined the significance of compiling accounting statements to report the changes in the stock and flow of natural resources. Based on an analysis of international practices and domestic practices, Lyu et al. (2020) borrowed the international norms of SEEA-2012 and found it was necessary to fully understand the preparation and use of natural resource assets and liabilities. The main body of preparing a NRBS requires the use of double-entry tables, which involves value accounting, and information from various departments.

Although studies have reported research on, and in-depth discussions about, natural resource asset accounting and preparation-related issues, a consensus is yet to be reached about the main points that should be included in the natural resource asset accounting framework, the accounting paths that should be followed, and the methods that should be employed. From a global perspective, it is undeniable that the latest authoritative guidance document for natural resource asset accounting issued by the United Nations (SEEA-2012) provides accounting and reporting models for the stock and flow of seven types of natural resource assets, and these are undeniably useful for natural resource asset accounting. Although the framework has guiding significance, it does not provide a clear definition of a NRBS, nor does it explain the format of its statement.

China's NRBS is currently in a trial compilation stage. To make NRBSs standardized and computerized, research is required to determine a structural framework design that includes liability theoretical issues (such as project accounting and asset value evaluation). In view of these requirements, we analyzed the composition of the major elements used in the NRBS and the measurement methods and data acquisition paths employed, as well as designed a specific report format for a NRBS.

\section{BASIC ELEMENTS WITHIN A NRBS}

To effectively prepare a NRBS, it is necessary to have a correct understanding of the natural resource accounting elements. However, the academic community has not yet reached a consensus about the elements that should be included in NRBSs, especially with respect to natural resource liabilities, and the opinions are quite divergent. Based on the classic accounting identity of "assets = liabilities + owner's equity," it is considered here that the basic elements of a NRBS should include natural resource assets, natural resource liabilities, and natural resource benefits. Using definitions from current representative research and the basic principles of accounting, these three elements are defined in the following sub-sections.

\section{Natural Resource Assets}

Researchers currently have a relatively unified understanding of the concept of natural resource assets. For example, Zhang et al. (2018) define natural resource assets as natural resources that are owned or controlled by the subject of property rights, and they bring certain economic benefits to this person. Li and Liu (2019) consider natural resource assets to be state-owned by the People's Government at all levels and by their subordinate departments and units. These assets were acquired through past statutory, authorization, or transactions, and they are owned by the state 
and managed, used, or controlled by the government and other social entities. Natural resources bring economic or ecological benefits to all stakeholders. Furthermore, Xu et al. (2019) suggested that natural resource assets are owned or controlled by the state, and they are expected to bring economic benefits to the country and the people.

Natural resource assets are a general term used to describe various natural materials that can be measured in currency, and it is not difficult to see that two basic premises are used in defining them. One is to emphasize "ownership," the status of the subject, and the other is to meet the "increased expected benefit". This definition conforms to the conceptual framework of accounting, and thus, this consideration of natural resource assets in the current study follows this definition. Therefore, in this study, natural resource assets are considered to be owned or controlled by the state authorized by the people's governments (at all levels and by all subordinate departments), and they are expected to bring certain economic benefits to all those with social rights and interests. According to this definition, the specific elements of natural resource assets include water, land, forest, grassland, marine, and wetland resources. Under these resource categories, there can be further secondary categories. For example, land resources can be further subdivided into agricultural, construction, and unused land according to land use. Forest resources can be divided into shelter, timber, economic, firewood, and special-purpose forests, according to their functions.

\section{Natural Resource Liabilities}

The definition of natural resource assets differs considerably from that of natural resource liabilities, and some researchers deny the existence of natural resource debt for three reasons. First, as natural resources will continue to change over time and with increasing social productivity, they will have greater uncertainty. As such, the current level of technology will be unable to specifically confirm the level of liabilities of these natural resources. Second, according to the general definition of a NRBS, the accounting entity of natural resources is generally a national government department; however, natural resource consumption entities include enterprises, natural persons, and other individuals in society. If liabilities are recognized at this time, there will be uniqueness in the statement preparation entity and contradiction between the decentralization of economically applicable subjects. Third, contemporary relatively standardized systems, such as the SEEA-2012, do not clearly require the recognition of liabilities (Geng et al., 2015; Cruz et al., 2019; Opaluch, 2020; Sharma et al., 2021b).

However, other researchers suggest that liabilities should be recognized in a NRBS because if they are not considered, it does not conform to the principle of prudence in our accounting. Moreover, according to the definition "assets = liabilities + owner's equity (net assets)," natural resource liabilities should also be recognized on a NRBS (Chen et al., 2015; Tao et al., 2020; Sharma et al., 2021c).

Considering that the original intention of compiling a NRBS was to clarify resource liabilities and report the flow and stock of natural resources with greater clarity and accuracy, resource liabilities should be recognized in this study. However, it is unclear how they should be defined if included in a NRBS. Gao (2016) considered that if resource extraction does not exceed a reasonable limit, resource liabilities should be a resource reduction, and if resource extraction exceeds a reasonable tolerance, resource liabilities should include environmental liabilities. Shi (2015) considers that natural resource liabilities should be recognized as our request for resources and its damage to the ecological environment. In Feng et al. (2017), natural resource liabilities relate to resource overconsumption, environmental damage, and ecological damage caused by the development and utilization of natural resources within a certain period in the past. Based on these perspectives and the definition of liabilities in accounting theory, natural resource liabilities should be the environmental damage caused by natural resource extraction, which includes resource depletion using currently employed mining methods and ecological damage caused by over-exploitation.

\section{Natural Resource Benefits}

The author suggests that based on the previous definitions for natural resource assets and liabilities, and according to accounting protocol, natural resource assets minus natural resource liabilities should equal natural resource benefits, which include economic and environmental benefits. These are defined as follows.

\section{Economic Benefits}

According to the definition of natural resources given in the "China National Accounting System (2016)," natural resources can be directly used for economic production, consumption, or accumulation through harvesting, mining, or extraction, or to provide space for exploitation of the economic activities of natural entities. This definition clearly emphasizes the usefulness and economic value of resources. In reality, natural resources are mostly exploited and utilized for economic purposes. For example, companies extract petroleum resources to process them into gasoline and sell them to consumers to obtain economic benefits. Fujian, China, is an area rich in natural resources, and the economic growth benefits of natural resources are more typical. Therefore, to calculate the economic benefits obtained from natural resource assets, we used SPSS20.0 statistical software to empirically analyze the correlation between two natural resource projects and related GDP data from 2010 to 2019 in Fujian, China. The original data analysis is presented in Table $\mathbf{1 .}$

The regression analysis results of selected variable data gave an $\mathrm{R}$-squared value of 0.970 for the equation, and the adjusted $\mathrm{R}$-squared value was 0.955 , which indicated a good model fit. The calculated coefficients are listed in Table 2 . The $t$ value of the forest coverage rate was 0.498 , and the corresponding significance level was 0.036 , which indicated that the forest coverage rate was positively correlated with the gross production value. Furthermore, the $\mathrm{t}$ value of the crop sown area was 1.955, which corresponded to a significance level of 0.098 and indicated that the sown area of crops was positively correlated with the GDP at the $10 \%$ level. The $t$ value of the total energy consumption was 7.076, and the corresponding significance level was 0.000 , which implied that the total energy consumption and GDP were positively correlated at the $1 \%$ level. Thus, it is evident 
TABLE 1 | Energy, crops, forests and other natural resource projects and regional GDP data in Fujian Province.

\begin{tabular}{|c|c|c|c|c|}
\hline Time & $\begin{array}{l}\text { Total energy consumption } \\
(10,000 \text { tons of } \\
\text { standard coal) }\end{array}$ & $\begin{array}{c}\text { Sown area of } \\
\text { crops (thousand hectares) }\end{array}$ & $\begin{array}{c}\text { Forest } \\
\text { cover rate (\%) }\end{array}$ & $\begin{array}{c}\text { Gross regional product } \\
\text { (100 million yuan) }\end{array}$ \\
\hline year 2010 & 9189.42 & 1941.20 & 63.10 & 12236.50 \\
\hline year 2011 & 9980.23 & 1878.36 & 63.10 & 15002.51 \\
\hline year 2012 & 10479.44 & 1801.75 & 63.10 & 17917.70 \\
\hline year 2013 & 10898.51 & 1758.29 & 65.95 & 20190.73 \\
\hline year 2014 & 11794.37 & 1703.13 & 65.95 & 22503.84 \\
\hline year 2015 & 11862.79 & 1658.18 & 65.95 & 24942.07 \\
\hline year 2016 & 12035.99 & 1589.33 & 65.95 & 26819.46 \\
\hline year 2017 & 12554.74 & 1592.10 & 65.95 & 29609.43 \\
\hline year 2018 & 13131.01 & 1621.42 & 66.80 & 33842.44 \\
\hline year 2019 & 13718.31 & 1648.03 & 66.80 & 42395.00 \\
\hline
\end{tabular}

Note: The data comes from "Fujian Statistical Yearbook 2011-2020"

TABLE 2 | The linear regression results of Fujian Province's regional GDP and natural resource projects.

\begin{tabular}{|c|c|c|c|c|c|}
\hline & \multicolumn{2}{|c|}{ Non-standardized coefficient } & \multirow{2}{*}{$\frac{\text { Standard coefficient }}{\text { Trial version }}$} & \multirow[t]{2}{*}{ t value } & \multirow[t]{2}{*}{ Sig. } \\
\hline & B & Standard error & & & \\
\hline Constant term & -180.566 & 32.649 & & -1.191 & 0.278 \\
\hline Forest cover rate & -495.320 & 994.293 & -0.083 & 0.498 & 0.036 \\
\hline Sown area of crops & 25.106 & 12.844 & 0.337 & 1.955 & 0.098 \\
\hline Total energy consumption & 8.638 & 1.221 & 1.350 & 7.076 & 0.000 \\
\hline
\end{tabular}

that there was a significant positive correlation between Fujian's natural resource projects and GDP, which confirms the economic benefits of these natural resources.

\section{Environmental Benefits}

The environmental benefits of a natural resource are mainly a measure of the environmental consequences of associated human social activities, which may be positive or negative. Of these, positive environmental benefits refer to spiritual and material values that natural environments provide to humans and animals, such as fresh air, pure drinking water, certain food, and aesthetically pleasing scenery that enhances human existence. In contrast, negative social benefits are associated with environmental destruction due to excessive development and the consumption of natural resources that threaten physical and mental health and the survival of animals and plants. Thus, to achieve positive environmental benefits, natural resources must be protected and used sustainably.

\section{METHODS USED FOR MEASURING NATURAL RESOURCE ITEMS AS BALANCE SHEET ITEMS AND FOR ACQUIRING DATA}

\section{Method Used to Measure Natural Resource Items on the Balance Sheet}

Based on a pilot exercise involving the compilation of a Chinese NRBS, two accounting methods-one that utilizes physical quantities and the other that utilizes value quantities-are mainly used for natural resource asset-liability projects. In this respect, the accounting of physical quantities uses statistics or technical methods to measure changes in the flow and stock of natural resources within a certain period, and the accounting of value quantities estimates the monetary value of each asset and liability item using physical quantity accounting. The types of accounting methods used include market and non-market methods. I suggest that a natural resource asset-liability project should adopt a measurement method that combines the accounting of physical and value quantities, wherein measurements are mainly determined by the inherent properties of the natural resources. Natural resources have natural, economic, and public attributes. Of these, natural attributes mainly manifest as the existence of natural resources, economic attributes are mainly the economic value of the natural resource that is realized through property rights or transactions in human production and life (such as land value and water resource value), and social attributes are mainly the external effects produced by natural resources, such as their ecological and environmental functions.

Therefore, to fully realize the accounting and characterization of natural resource assets, it is necessary to comprehensively examine the attributes of various aspects of natural resources, including the types of resources, total scale, and resource values. Calculation of the total scale of resources is generally realized by calculating physical quantities, and characterization of the value of resources is realized by calculating their value. For example, for natural resources that can be traded within a market, such as land and biological resources, the market price of the resource at the time of accounting is considered to be the basis for conducting measurements. For natural resources that cannot be traded, it is necessary to explore the use of accounting methods that employ 
Unified natural resource

balance sheet rules
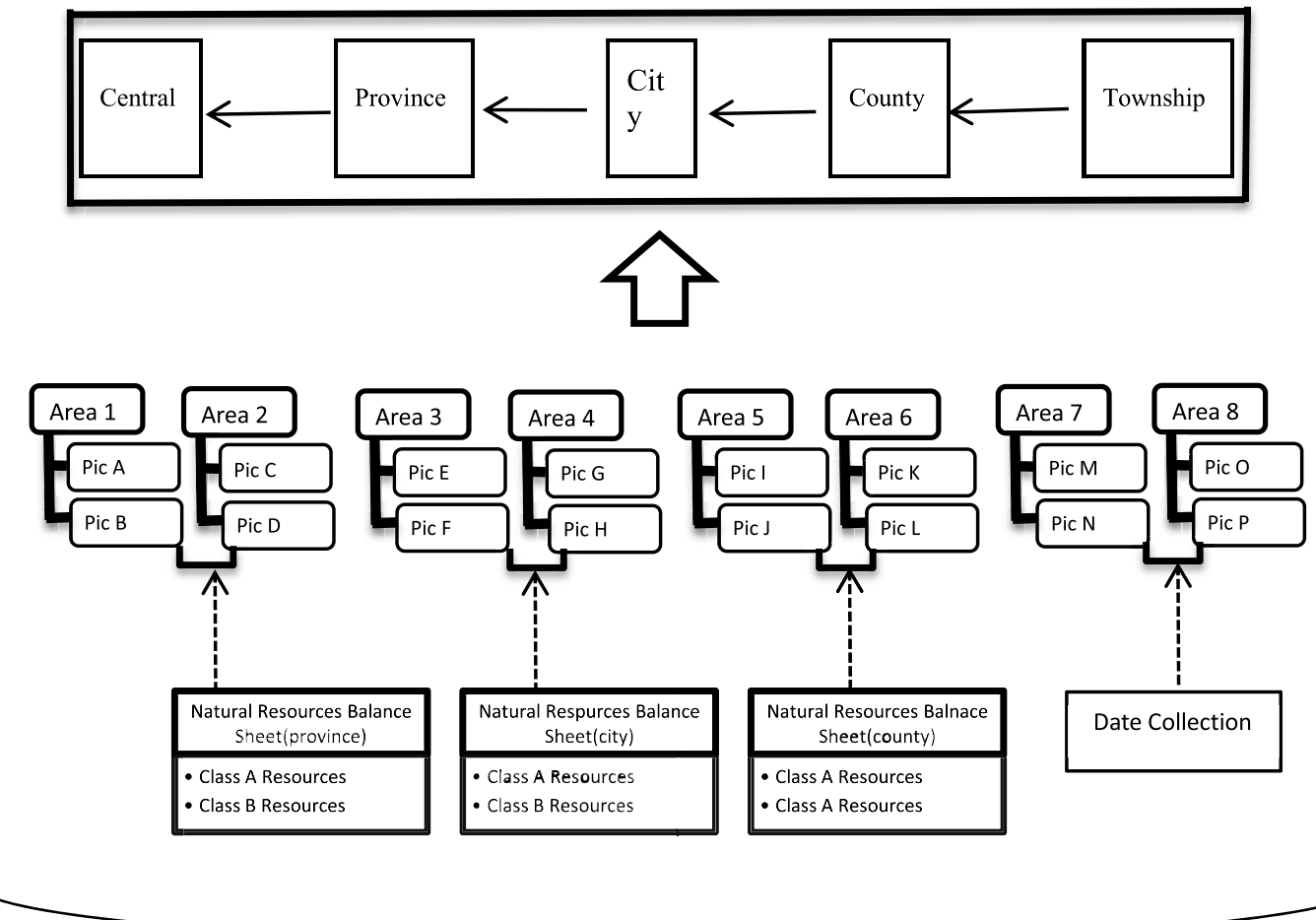

Date Collection

Electronic information system

FIGURE 1 | Data acquisition path of natural resources balance sheet items.

the ecological value of natural resources (Mancini et al., 2018; Shi and Wang, 2020; Sharma et al., 2021d).

\section{Acquiring Data for Natural Resource Balance Sheet Items}

Accurate acquisition of original data for natural resource assets and liabilities is necessary for preparing NRBSs. Most NRBSs are currently compiled using relevant data from various local statistical yearbooks. Most of these data are relatively rough, and it is challenging to use them to compile a NRBS. Thus, it is necessary to have access to a complete network of relevant data, to compile a NRBS.

From the perspective of the compiler of natural resources balance sheet, the state should provide instructions on the method used to complete the NRBS with the participation of villages, townships, towns, counties, and city governments. In this respect, the state should formulate unified accounting methods, accounting subjects, report formats, and other related specifications. It should then prepare each county's NRBS by considering that each county is a unit. Each city and province should then submit a NRBS, and the central government should then compile the nation's NRBS. Counties could simplify rural, township, and township statistics within the NRBS to enable statisticians to complete the form without too much relevant knowledge. The method used to acquire data for the NRBS compiled in this study is shown in Figure $\mathbf{1}$ and described in detail below.

First, the rules and regulations for preparing NRBSs should be unified. The central government should formulate a unified national accounting system for statements, and provinces, 
cities, counties, towns (townships), and villages should strictly follow the relevant accounting system methods when preparing NRBSs and collecting data. For example, a unified NRBS table format should be developed that includes accounting subjects, so that it can be seamlessly connected when consolidating reports level by level. If differences exist between the major categories of natural resources of various regions and there are no major resource categories in a particular region, the column can be summed as zero. Each natural resource sub-category can be compiled into a subsidiary account according to the specific conditions of each region. However, the accounting rules for this subsidiary account should also be consistent across the country, to ensure that supervision is easy and that obtaining information from the accounting books is possible.

Second, a unified method for the recognition, measurement, and recording of natural resource assets and liabilities should be developed. The same method should be used in all regions and for different accounting periods within the same region. This would avoid making underestimations or overestimations due to the use of different measurement methods, natural resource assets, and liabilities, while avoiding the difficulty of consolidating NRBSs level by level because of the different methods used in different regions.

In addition, in relatively remote places, such as villages and towns, it is not appropriate to prepare separate NRBSs for two reasons. First, many children and elderly people live in villages and towns, and many have a low level of education. If separate reports are required, a longer period of training would be required, and preparing the report would be difficult. Second, the labor costs for compiling the report would be too high. Personnel would be required not only to collect basic data and record items in the accounting sheets, but also to record all kinds of account books and prepare and adjust the reports. Such a set of staffing already requires high labor costs, and the statistical workload of a village or even a town's natural resources will not be balanced with such staffing. In other words, the workload would exceed the amount that the staff can accommodate. Therefore, only basic data entry is required in villages, towns and so on.

Second, a person in charge should be identified and their responsibilities and obligations must be clearly stated. Such a person should be designated in each regional unit of natural resources, and they would be responsible for accounting the types, quantities, and damage levels of natural resources within the region. If there are many natural resources, labor can be appropriately increased. For example, the person in charge, named "A," is responsible for the Class A resources in Area 1 (including the assets, liabilities, and corresponding resource benefits of Class A resources). In the process of natural resource accounting, statistics of the physical quantity of natural resources only need to provide the corresponding natural resource data sources, statistical scope, and statistical methods, and the person in charge does not require professional accounting knowledge. However, the NRBS also involves the calculation of the value of natural resources. Therefore, the person in charge of the preparation of the NRBS not only requires knowledge of accounting, but also requires a certain understanding of the natural resources in the area in which they are responsible. Additionally, to ensure the authenticity of the data in the statements, it should be stipulated that each person in charge will be responsible for the data on the natural resources balance sheet during their tenure within two to 3 years after leaving their post.

Finally, an electronic information system is required for storing and processing data throughout the entire process, from the collection and recording of the most basic data to the completion of the final NRBS preparation and consolidation. Electronic information systems or smart technologies are used for data processing, which not only greatly reduces the labor cost of natural resource data statistics, but also improves the accuracy of natural resource data information. Considering the complexity of the electronic information system and limitation of the knowledge level of the person in charge of natural resource data collection in a township, each person in charge only needs to be responsible for the simple recording and uploading of natural resource data.

\section{CONSTRUCTING A SYSTEM FRAMEWORK FOR THE NRBS}

\section{Reporting System and Format Reporting System}

Taking the natural resource management department of the county-level government as the accounting entity as an example, the report system data are generally formed through internal and subordinate reporting and aggregation. Regarding internal data formation, the natural resource management department should register the natural resources in the central area of the county and perform regular accounting, conduct inspections and audits at the end of each quarter, and finally summarize them at the end of the year. In this way, a natural resource accounting table in the central area of the county is formed. The main table is the NRBS, and the sub-tables are the natural resource asset, natural resource liability, and environmental benefit change tables. If necessary, a number of auxiliary tables can be added, such as trial balance or resource flow tables. Additionally, data in sub-tables submitted at lowerlevel units, such as villages, towns, and townships need to be summarized at the end of the accounting period. If these lowerlevel organizations in villages and towns have special circumstances, such as insufficient statistical talent and limited professional knowledge, they only need to collect basic data, and there is no need to form a professional and complete NRBS.

\section{Report Format}

The NRBS can be presented in either a symmetric or a matrix format. The left-hand side of a symmetrical report lists the natural resource asset projects, and the right-hand side lists the natural resource liabilities and natural resource benefit projects. The columns are set at the beginning and end of the period, and the physical quantities and their units and values are set separately below. The matrix report adopts the SNA mode, referring to the format of the National Economic Accounting System (2008 edition) for presentation. The main word column is the listing of the balance formula, and the object column is the 
TABLE 3 | Natural resources balance sheet.

\begin{tabular}{|c|c|c|c|c|c|c|c|c|c|}
\hline \multirow[t]{2}{*}{ Natural resource assets } & \multicolumn{2}{|c|}{ Opening balance } & \multicolumn{2}{|c|}{$\begin{array}{l}\text { Ending } \\
\text { balance }\end{array}$} & \multirow[t]{2}{*}{$\begin{array}{c}\text { Natural resource liabilities } \\
\text { and benefits }\end{array}$} & \multicolumn{2}{|c|}{ Opening balance } & \multicolumn{2}{|c|}{$\begin{array}{l}\text { Ending } \\
\text { balance }\end{array}$} \\
\hline & Physical quantity & unit & Value & unit & & Physical quantity & unit & Value & unit \\
\hline 1. Water resources & & & & & Water loss & & & & \\
\hline Of which: surface water & & & & & Land resource depletion & & & & \\
\hline groundwater & & & & & Energy resource depletion & & & & \\
\hline Subtotal & & & & & Depletion of forest resources & & & & \\
\hline 2. Land Resources & & & & & Cope with pollution control liabilities & & & & \\
\hline Of which: agricultural land & & & & & Of which: wastewater treatment & & & & \\
\hline Construction land & & & & & Pay environmental compensation fees & & & & \\
\hline Other land & & & & & Of which: Compensation for water pollution & & & & \\
\hline Subtotal & & & & & Subtotal of natural resource liabilities & & & & \\
\hline 3. Energy Resources & & & & & Natural resource benefits & & & & \\
\hline Of which: renewable & & & & & 1. Economic benefits of natural resources & & & & \\
\hline Nonrenewable & & & & & Of which: surplus distribution & & & & \\
\hline Subtotal & & & & & Surplus retention & & & & \\
\hline 4. Forest resources & & & & & 2. Environmental benefits of natural resources & & & & \\
\hline Of which: forest resources & & & & & Air purification & & & & \\
\hline Soil microorganisms & & & & & Renewable resources & & & & \\
\hline Subtotal & & & & & Subtotal of natural resource benefits & & & & \\
\hline Total natural resource assets & & & & & Total natural resource liabilities and benefits & & & & \\
\hline
\end{tabular}

listing of the relevant departments (regions), which is balanced vertically and horizontally. Only symmetrical reports are referred to in this study, and the NRBS compiled in this study is shown in Table 3.

\section{Accounting System and Structure}

A NRBS is compiled to provide relevant information and reflect the continuous changes in natural resource assets and ownership relationships. This is achieved by establishing an accounting system that can confirm, measure, record, and statistics during daily accounting. It is necessary to establish accounts according to the classification of natural resource assets, natural resource liabilities, and natural resource benefits, as well as to select an account structure according to the position of the account in the balance formula. According to the principle of double-entry bookkeeping, to maintain the balance formula during the accounting process, the account structure at the left side of the formula should be set to "left increase and right decrease," and the account structure at the right side of the formula should be set to "right increase and left decrease." At the end of the period, all accounts with a balance on the left belong to the left end of the equation and are asset accounts; moreover, all accounts with a balance on the right belong to the right end of the equation and belong to the debt benefit account. The balances on both sides of the account are equal, and the formula is established. The doubleentry bookkeeping method, which originated in the west, uses the word debit and credit as bookkeeping symbols, and follows the rule of "left borrowing and right lending," i.e., the asset account is recorded as a "debit increase and credit decrease," and the liability benefit account is recorded as a "credit increase, debit, and decrease." As the words "debit" and "loan" have lost their original meaning in accounting, they only represent the direction of increase or decrease of accounts of different nature. Therefore, when the self-debit and credit bookkeeping method was introduced into China, some people suggested replacing the words "debit" and "credit" with Chinese bookkeeping symbols, so-called "left and right bookkeeping". This term is easier to understand than "debit and credit accounting method" and can better promote the development of work to prepare the NRBS of the township.

\section{Change in Accounting Item Types and Balance of Trial Calculations at the End of the Period \\ Change in Accounting Item Types}

Compiling a NRBS involves accounting for natural resource assets, natural resource liabilities, and natural resource benefits, and the balance formula is as follows: natural resource assets $=$ natural resource liabilities + natural resource benefits. Although the "left and right bookkeeping method" was used in this study, it was essentially the same as the "debit and credit bookkeeping method." That is, each item type in the account has two parties $(2 \times 2 \times 2=8)$, and there are eight categories of accounting items, which are described as follows. In the first category, the natural resource asset category subjects increase and decrease, and the amount of increase and decrease is equal, and the balance relationship remains unchanged. In the second category, the natural resource liability category subjects increase and decrease, and the amount of increase and decrease is equal but the balance relationship is not. In the third category, the amount of increase and decrease between the natural resource benefit subjects is equal, and the balance relationship remains unchanged. In the fourth category, the increase and the other decrease between the natural resource liability subjects and the natural resource benefit subjects; the amount of increase or decrease is equal, and the balance relationship remains unchanged. In the fifth category, the natural resource asset category and the natural resource liability category increase at the same time, the amount is equal, and the balance relationship 
remains unchanged. In the sixth category, which comprises the natural resource asset category and the natural resource benefit category, the subjects increase at the same time, the amount is equal, and the balance relationship remains unchanged. In the seventh category, the natural resource asset category and the natural resource liability category decrease at the same time, the amount is equal, and the balance relationship remains unchanged. In the eighth category, which comprises the natural resource asset category subject and natural resources, the benefit subjects are reduced at the same time, the amount is equal, and the balance relationship remains unchanged.

\section{Trial Balance}

At the end of the accounting period, all accounts are balanced, and a trial balance sheet is prepared for audit verification. When the beginning, end, and balance of the period are equal on the left and right, the accounts can be settled and the NRBS and its subtables are prepared.

\section{CONCLUSION}

We analyzed the basic elements within a NRBS, the associated measurement methods, and the data acquisition paths and constructed a system framework for natural resource assetliability project accounting. The main conclusions of this study are as follows:

1. The basic elements of a NRBS should include the natural resource assets, natural resource liabilities, and natural resource benefits; of these, the natural resource benefits include economic and environmental benefits (Sharma and Mahendru, 2017).

2. A measurement method, which employs a combination of both physical and value quantities, should be used to quantify the natural resource assets and liabilities.

3. To obtain reliable natural resource asset and liability data, the following are a pre-requisite: the rules and regulations for

\section{REFERENCES}

Alfsen, K., Bye, T., and Lorentsen, L. (1987). Natural Resource Accounting and Analysis-The Norwegian Experience1978-1986. Statistisk sentralbyrå 12 (29), 71.

Bansal, S., Sharma, G. D., Rahman, M. M., Yadav, A., and Garg, I. (2021). Nexus between Environmental, Social and Economic Development in South Asia: Evidence from Econometric Models. Heliyon 7 (1), e05965. doi:10.1016/ j.heliyon.2021.e05965

Burritt, R. L., and Saka, C. (2006). Environmental Management Accounting Applications and Eco-Efficiency: Case Studies from Japan. J. Clean. Prod. 14 (14), 1262-1275. doi:10.1016/j.jclepro.2005.08.012

Chen, Y., Gong, R., and Zhao, H. (2015). On the Preparation of Natural Resources Balance Sheet: Theoretical Basis, Key Concepts and Framework Design. Account. Res. 2015 (09), 18-26.

Cruz, A., Reyes, T., and Vassolo, R. (2019). Liability of Middleness Revisited: the Advantages for Mid-sized Competitors in Renewable Natural Resource Industries. Manage. Organ. Rev. 15, 737. doi:10.1017/mor.2018.54

Feng, Z., Yang, Y., Yan, H., Pan, T., Dong, J., and Xiao, C. (2017). Issues Regarding the Compilation of the Natural Resource Balance Sheet. Resour. Sci. 39 (09), 1615-1627. doi:10.18402/resci.2017.09.01 preparing NRBSs should be unified; a person in charge should be appointed, and their corresponding responsibilities and obligations should be clearly stated; and an electronic information system should be established for storing and processing process data throughout the entire process (Yan et al., 2021).

4. According to the basic elements of a NRBS, including the natural resource assets, natural resource liabilities, and natural resource benefits, the basic balance formula for natural resource asset-liability project accounting is as follows: natural resource assets-natural resource liabilities $=$ natural resource benefits (Zutshi et al., 2021).

\section{DATA AVAILABILITY STATEMENT}

The original contributions presented in the study are included in the article/Supplementary Material, further inquiries can be directed to the corresponding author.

\section{AUTHOR CONTRIBUTIONS}

PC: Writing-original draft, Supervision. HX: Conceptualization, Methodology. SC: Project administration. YS: Software, Resources. BZ: Writing-review and editing, Funding acquisition. XZ: Formal analysis, Investigation, Validation.

\section{FUNDING}

This work was supported by 2021 University Collaborative Innovation Project (Grant No. GXXT-2021-048), the Major Projects of Social Science Base in Fujian Province (Grant No. FJ2018JDZ003), Joint Project on Science and Technology Innovation Strategy Research in Fujian Province (Grant No. 2020R0139).

Gao, M. (2016). Comprehensive Accounting of Natural Resources-Focusing on the Balance Sheet of Natural Resources. Stat. Res. 33 (1), 4-12. doi:10.3969/ j.issn.1002-4565.2016.01.002

Geng, J., Hu, T., and Liu, Z. (2015). The Research on Preparation and Application of China's National Balance Sheet and Natural Resources Balance Sheet. Account. Res. 2015 (01), 15-24.

Gerlagh, R., Dellink, R., Hofkes, M., and Verbruggen, H. (2002). A Measure of Sustainable National Income for the Netherlands. Ecol. Econ. 41 (01), 157-174. doi:10.1016/s0921-8009(02)00021-6

Goldsmith, R., and Lipsey, R. (1965). Studies in the National Balance Sheet of the United States. J. Finance 127 (03), 84-85.

Kassai, J., Feltran-Barbieri, R., Carvalho, N., Cintra, Y., Santos, F., and Luiz (2012). Balance Sheet of Nations Environmental: A Reflection in the Scenario of Climate Change. Braz. Bus. Rev.. 9 (1), 60-102.

Li, Y., and Liu, G. (2019). A New Breakthrough of Natural Resources Accounting in New China. Account. Res. (12), 11.

Lyu, X., Liu, S., and Geng, J. (2020). Key Issues in the Preparation and Application of Natural Resource Balance Sheets in China. China Popul. Resour. Environ. 30 (4), 9.

Mancini, M., Galli, A., Coscieme, L., Niccolucci, V., Lin, D., and Pulselli, F. (2018). Exploring Ecosystem Services Assessment through Ecological Footprint Accounting. Ecosyst. Serv. 30, 228, 2018 , S2212041617301390. doi:10.1016/ j.ecoser.2018.01.010 
Morehouse, E. W., and Ely, R. T. (1924). Elements of Land Economics. New York: Macmillan.

Obst, C., and Vardon, M. (2014). Recording Environmental Assets in the National Accounts and the Australian Experience. Oxf. Rev. Econ. Policy. 30 (01), 126-144.

Opaluch, J. (2020). Liability for Natural Resource Damages from Oil Spills: a Survey. Int. Rev. Environ. Resource Econ. 14, 37. doi:10.1561/101.00000114

Sharma, G. D., and Mahendru, M. (2017). Thirst for a New Management Theory. Asian Jour. Manag. 8 (3), 921. doi:10.5958/2321-5763.2017.00141.x

Sharma, G. D., Shah, M. I., Shahzad, U., Jain, M., and Chopra, R. (2021b). Exploring the Nexus between Agriculture and Greenhouse Gas Emissions in BIMSTEC Region: The Role of Renewable Energy and Human Capital as Moderators. J. Environ. Manage. 297 (May), 113316. doi:10.1016/j.jenvman.2021.113316

Sharma, G. D., Talan, G., Bansal, S., and Jain, M. (2021c). Is There a Cost for Sustainable Investments: Evidence from Dynamic Conditional Correlation. J. Sust. Finance Investment, 1-21. doi:10.1080/20430795.2021.1874215

Sharma, G. D., Tiwari, A. K., Erkut, B., and Mundi, H. S. (2021d). Exploring the Nexus between Non-renewable and Renewable Energy Consumptions and Economic Development: Evidence from Panel Estimations. Renew. Sust. Energ. Rev. 146 (January), 111152. doi:10.1016/j.rser.2021.111152

Sharma, G. D., Tiwari, A. K., Talan, G., and Jain, M. (2021a). Revisiting the Sustainable versus Conventional Investment Dilemma in COVID-19 Times. Energy Policy 156 (February), 112467. doi:10.1016/j.enpol.2021.112467

Shi, D. (2015). Natural Resources Balance Sheet: Chinese Characteristics and International Practices. China Economist 10 (04), 22-43.

Shi, D., and Wang, J. (2020). Research Status, Literature Review and Improvement Direction of the Natural Resource Balance Sheet. China Popul. Resour. Environ. $30(01), 1-11$.

Tao, J., Lyu, Y., He, L., and Shen, L. (2020). Research on Land Resources Assets Accounting and Statement Formulation Based on Double Accounting. China Popul. Resour. Environ. 30 (01), 22-29.

Wang, S., and Yuan, Z. (2020). Research on the Formulation of Marine Resources Balance Sheet. China Environ. Manage. 12 (3), 61-63. doi:10.16868/j.cnki.16746252.2020 .03 .061
Xu, S., Zhang, S., and Chen, L. (2019). Analysis on the Compilation of Natural Resources Balance Sheet. Finance Account. Monthly 2019 (001), 79-85. doi:10.19641/j.cnki.42-1290/f.2019.01.012

Yan, Y., Shah, M. I., Sharma, G. D., Chopra, R., Fareed, Z., Shahzad, U., et al. (2021). Can Tourism Sustain Itself through the Pandemic: Nexus between Tourism, COVID-19 Cases and Air Quality Spread in the 'Pineapple State' Hawaii. Curr. Issues Tourism, 1-20. doi:10.1080/13683500.2021.1965553

Zhang, W., Wang, H., and Guo, J. (2018). Objective and Accounting Framework of Natural Resources Balance Sheet. Environ. Protection 46 (01), 39-42. doi:10.14026/j.cnki.0253-9705.2018.11.009

Zhao, X., Ma, X., Chen, B., Shang, Y., and Song, M. (2022). Challenges toward Carbon Neutrality in China: Strategies and Countermeasures. Resour. Conservation Recycling 176, 105959. doi:10.1016/j.resconrec.2021.105959

Zutshi, A., Mendy, J., Sharma, G. D., Thomas, A., and Sarker, T. (2021). From Challenges to Creativity: Enhancing SMEs' Resilience in the Context of COVID-19. Sustainability 13, 6542. doi:10.3390/su13126542

Conflict of Interest: The authors declare that the research was conducted in the absence of any commercial or financial relationships that could be construed as a potential conflict of interest.

Publisher's Note: All claims expressed in this article are solely those of the authors and do not necessarily represent those of their affiliated organizations, or those of the publisher, the editors and the reviewers. Any product that may be evaluated in this article, or claim that may be made by its manufacturer, is not guaranteed or endorsed by the publisher.

Copyright $\odot 2022$ Chen, Xu, Chen, Shang, Zhang and Zhao. This is an open-access article distributed under the terms of the Creative Commons Attribution License (CC $B Y$ ). The use, distribution or reproduction in other forums is permitted, provided the original author(s) and the copyright owner(s) are credited and that the original publication in this journal is cited, in accordance with accepted academic practice. No use, distribution or reproduction is permitted which does not comply with these terms. 